\title{
Analysis on the Product Package Design from the Perspective of Bionics Design
}

\author{
Chen Ling \\ College of Liberal Arts, Macau University of Science and Technology
}

\begin{abstract}
From the perspective of bionics design, this paper analyzes the product package design. It can be seen that through the application of product package modeling, color, material texture and other elements, the design can not only satisfy consumers in materials, but also make them feel joyful at the spiritual level, attracting the attention of consumers and improving their purchasing aspiration, so as to promote the sales of product.
\end{abstract}

Keywords-Bionics design; Perspective; Product; Package design

\section{INTRODUCTION}

All the initial creation activities of humans are obtained from the nature, and the development of package design is no exception. During the primitive period when humans lived in caves as groups, food was directly obtained from the nature, during which people didn't generate design awareness for objects. In order to make it convenient to store and carry, natural materials started to be used for package. For instance, during the early phase, shells were used to directly contain water for drinking; although such vessels are not designed and manufactured by human, they are actual packages, which have certainly enlightened the generation of man-made package design behaviors. After that, people slowly and gradually got familiar with the nature in the labor process, and gradually conquered the nature. Along with the era development and the constant accumulation of practical experience, people also have a new cognition and breakthrough in various materials, and designed various kinds of different models of commodities requested by people. Currently, the product package used by people is always a part of people's life, and the designer conducts design through utilizing different design methods, of which bionics design attracts the attention of consumers and favored by consumers; such bionics design can let the consumer better feel the beauty of nature. Experience the demand of human spirits, the harmony with nature, and the close contact with the beauty of nature in life.

Bionics design is bionics design science, and it is a new discipline derived on the basis of bionics and design science, and it mainly studies all living things in nature, and involves biology, ergonomics, materials, dynamics, chromatics, aesthetics, and other relevant disciplines [3]. It takes the force and the "color", "form", "sound", "function" and "structure" for all living things in nature as the research object, and the bionic objects are varied, the application field of bionics design is constantly expanded, with broad prospects, and since the starting point is different, the discipline, research method and research achievements involved thereby are also different.

In the endless nature, designers have inexhaustible natural resources, and creatively stimulate the nature in package design. Through conducting conditional selection, processing and representation on the basis of meeting bionics, designers can select and extract different elements therein and apply bionic techniques to design and reach to the product package of "nature and man in one" requested by people. Mr. Zhu Guangqian used to say that: "at the original period, beauty and usage were unified." Similarly, this is no exception when using bionic method to conduct package design, and it is also applicable to perfectly combine the external form of bionic beauty and the internal attribute of commodities. In the product package specialty, the principle of bionics design science is applied in the package design, and then analysis is conducted on the several forms of product package on the basis of the research from the perspective of bionics: modeling structure, appearance color, material texture expression and bionic form and biological similarity, and by virtue of art imagination, select and extract the typical art characteristics of nature; after that, conduct innovative simulation, provide conditions for imagination, use similarity analysis to ensure that the product attribute can be matched with the reasonability of bionics design, and then from the perspective of bionics design, conduct research from the perspective of bionics design through the different design languages of product package, analyze product package design, and make the visual impact for the entire product package effect stand out from the terminal sales of similar products, so as to realize the sales promotion of commodities, and promote the brand value of products.

\section{BIONIC MODELING STRUCTURE}

The bionic modeling structure of package design: the product package modeling structure is designed through stimulating the similarity between the internal and external structures of biology in combination with different product concepts, and the objective is to realize the similarity between the vessel modeling of product package or the external package of product and the biology, and since it is requested to consider whether the biological entity or local part should be used when using bionic creativity in the entire package modeling design, find out the biology with similar functions, so as to highlight the uniqueness of commodity package, carefully consider and study, match with the commodity attribute, to let consumer 
experience generate spiritual pleasure. There are many such successful cases, of which the product package designed by Russian Brand KIAN for its subordinated soymilk productSoy Mamelle is as shown below (Figure 1) [1], and this package is like the breast of a cow or goat, and skillfully convey the information that milk is a beverage; besides, color matching and decoration can convey the image focusing on phytogenesis and building natural health, and the package takes polyester materials or glass as the raw material, and the beverage has a simple bottle cap, and the three legs can perfectly support the round body of bottle, the vessel modeling for package adopts bionics design, and its creativity is from the breast of animal, and the model is like a breast, and the three legs supporting it are like the nipple; actually, soymilk also contains rich protein like the milk, and the contents of lipoid materials are lower, and it is a kind of relatively healthy beverage; the design of Soy Mamelle is like the appearance of dairy cattle, which can make you accept the replacement of animal milk with soymilk. This unique design of product package can attract attentions of consumers among similar products, and it can be more easily remembered by people; in case of making certain endeavors in product appearance or package, it will be certainly helpful to better promote product popularity, and largely promote product brand image.

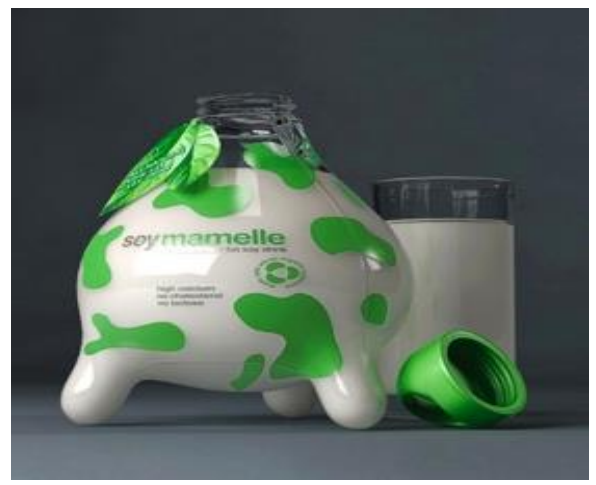

Fig. 1. Russian Brand KIAN Soymilk Package Design

\section{BIONIC COLOR CHARACTERISTICS}

The bionic color characteristics of package design: bionics design is mainly conducted through the simulation and evolution of organisms. Through the cognition or extraction of biological color, conduct relatively intuitive extraction and deduction considering the objectivity of biological color, the natural characteristics and significance [1]. Firstly, the color of natural biology is the characteristics and demand for life existence, and for some biology, the appearance color is consistent with the surrounding environment color, and its objective is to avoid the attack or ham of other organisms and protect itself in complicated environment, and for the design, it has applied the main contents bout the aesthetic perception of nature, and in the nature, there are many vivid and interesting color phenomena, regardless of biology and plants, the rich, numerous and complicated color relation and individualized characteristics are quite meaningful to product color, and has endless attraction and imagination for people. Therefore, in the eyes of designers, they should constantly find the beauty in life, with the aesthetic attainment higher than normal people, timely find the beauty in nature, constantly capture it and apply it in package design, stimulate the natural color of biology, apply it in the product package design, let consumers generate a sense of trust after seeing products with such package design and trigger their desire to buy, and the vivid bionic package will make the commodities stand out from the dazzling shelf. It can arouse the beautiful emotions of consumers about cherishing life. Being driven by such beautiful and harmonious atmosphere, it can deepen the impression of consumers on the beauty of nature for commodities and the intimate feeling with the ground, and also largely increase the selling opportunity of the product. Visually, the product package color bionics can better stimulate consumers, and in the package design, different color assortments also represent different tastes, evoke people' s memories and associations about certain fruit, and the expression of plants' leaves or flowers can evoke people's recall about the smell of certain flower, etc. if the bionic color is especially highlighted in essence or contains certain subsidiary significance, for instance, consumers will immediately associate with the characteristics and attribute of such product when seeing such package design, so this can save the attentions paid by consumers among many commodities, decrease the selection of consumers for other similar products, save the time for consumers to select commodities, and then exert the function of better stimulating consumers to buy commodities.

Many consumers recognize products placed on shelf through the color on the package, and it is very common to use bionic color design in product package. In large-scaled supermarket, the communication between consumers and commodities is often realized through the spiritual communication between the eyes and the commodity, and color is one of the visual elements to stimulate the senses of consumers, so it can build a silent communication bridge between the package design and the consumers, and play an important role in promoting the color visual impact of products.

\section{MATERIAL TeXTURE BIONICS}

The material texture bionics for bionic package design refers to stimulating the texture structure for the external appearance of natural objects. The texture refers to the organization texture structure on the surface of organisms in nature, and it expresses the feeling of people about the surface texture characteristics of designed objects, and stimulates the surface texture of natural organisms, and since different materials require different technical means, i.e., the so-called beautiful material and clever men, each material can have its own characteristics, which will be directly related to utensils and aesthetics.

Firstly, the visual expression of material texture relies on the eye vision to perceive the external characteristics, and it is a feeling and reflection of the material surface characteristics after the visual perception of materials and the brain processing Wright, the American Architect used to say that: "each material has its own language, and each material has its own story". The visual perception firmed by the form, texture, color, and gloss, etc. of different materials is different [2]. The application in the product package design process can improve the individualized characteristics of package. Currently, people's environment 
protection awareness has been constantly improved, so the product package conducted for the stimulation of texture materials in nature can conform to the requirements of consumers and also evoke their mentality of shopping security. This is also a reason for consumers to select bionic package.

Secondly, the biological texture in nature also has certain growth direction (such as trees), so it is applicable to conduct purposeful option design as per product characteristics. Some of them directly use bamboo pipes to hold commodities, and conduct different package applications, which can bring a brand new visual perception to people and let people feel the intimacy between nature and life [4].

The product package material texture bionics can not only let consumers feel that they are close to natural life, but also promote consumers' trust degree in products; currently, some packages use different printing technologies to represent and change the effect of different textures. It is a kind of colorful art paper for which the surface has various textured pattern texture, and it can increase the sense of preciousness and attempt to skillfully apply the natural texture and man-made texture of the material to conduct interesting package design with different textures, so as to reinforce the individualized performance of commodity package, reach to the effect that is unreachable for visual pattern and texture. Besides, it has also stimulated the desire of consumers to buy it, and stimulate people's urgent demand to buy it.

Materials should keep pace with the times: as the carrier of package design, all designs can only present different product packages through materials, including the commodity package modeling and its color. Currently, the occurrence of synthetic materials has also entered into the field of bionic product package design, and the occurrence of new materials has triggered the inspiration of designers for creative design. To conduct package design confirming to the era, fashionable package design can always be accompanied by the generation of new science and technology, and the package design must rely on the era. In case of being separated from era characteristics, the product package design will always be eliminated by consumers in the drastic commercialized society, so bionic product package design has also been involved with the development of era, and through the innovation of modeling and materials in combination with the synchronization with era characteristics, some basic bionic elements are given full play in package design, more reasonably combined with product structure and can let people feel about more product package designs with modern bionics.
The USB interface used for charging adopts bionic package design, and the synthetic material package presented thereby is combined with the product function, and present the pod structure in nature and the colorful product package design. There is one USB socket at the side of each pod, looking like a pod, but actually, it is a multi-socket USB interface, which is elegant and beautiful. New materials and products occur due to the development of era, so various products favored by people can be designed through adopting utilizing the bionic principle and adopting synthetic materials. It is favored by consumers in the market.

Thus, it is requested to pay constant attention to the new trend of materials and technologies, and only by doing so can outstanding package design scheme be created, and the competitive advantage be constantly kept among similar products in the market.

\section{CONCLUSION}

Along with people's constant in-depth research on bionics design, it will bring more creative development spaces for product package design; it can find out the market demand from the perspective of bionics while standing on the front edge of the era, design better, and meaningful product package design that more conforms to the intention of consumers, so as to realize the objective of sales promotion.

\section{REFERENCES}

[1] http://www.toodaylab.com/17086

[2] Gao Liyan. Application of Plant Materials in Green Package Design [J]. Packaging World, 2014-07-25.

[3] Zheng Xiaona. Research on the Development and Application of the New Mode of Modern Package Design , Master Thesis of Tianjin University of Technology, 2011-12-01.

[4] Liu Xing. Research on the Application of Multi-sensory Expression in Modernized Visual Communication Design [J]. Beauty and Age, 2014$12-15$.

[5] Li Hong. Enlightenment of Bionics Design for Modern Package Design [J]. Journal of Suzhou University, 2010, 25 (10): 76-78.

[6] https://zhidao.baidu.com/question/1671837726861263027. html

[7] Jiang Yiyi. Application of Bionic Form in Vessel Package Design [J]. Art Theory, 2010 (5): 199

[8] Gu Bo. Research on Era Demand of Modern Package Bionics Design [J] Packaging Engineering, 2011(6): 112-115.

[9] Liang Pei. Application of Bionics in Package Design [J]. Modern Decoration. 2012 (4):18-18 